\title{
Acompanhamento Terapêutico: História, Clínica e Saber
}

\author{
Therateutic Accompaniment: \\ History, Clinic and Knowledge \\ Acompañamiento Terapéutico: \\ Historia, Clinica y Saber

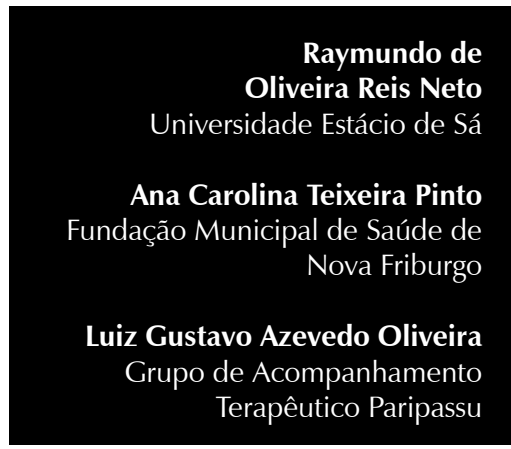

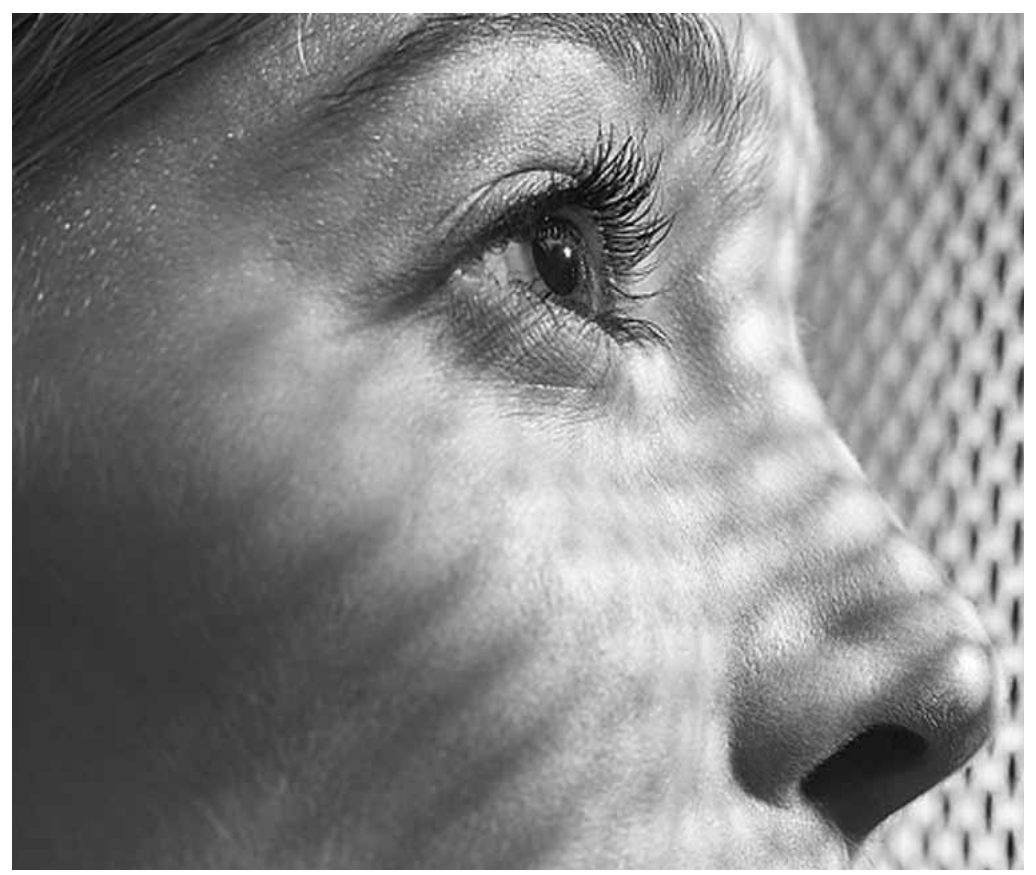


Resumo: Abordando o acompanhamento terapêutico (AT) de uma perspectiva histórica, o artigo tem como objetivo enfocar algumas transformações pelas quais essa modalidade de tratamento passou desde seu surgimento, mostrando sua relevância para a compreensão e o enfrentamento de alguns desafios com que se depara hoje. Destacando mudanças que concernem tanto a demanda por essa prática como os seus objetivos e o perfil daquele que a desempenha (AT), focalizamos a emergência e os desdobramentos de uma preocupação dos acompanhantes terapêuticos com o manejo do vínculo e da escuta. Tal preocupação os tem conduzido a um esforço de sistematização teórica do acompanhamento terapêutico que levanta importantes questões acerca da relação do AT com o saber que o credencia a praticar sua função.

Palavras-chave: Acompanhamento terapêutico. Terapeuta. Psicanálise. Aquisição do conhecimento.

Abstract: Discussing therapeutic accompaniment (TA) from a historical perspective, the article`s objective is to focus on some transformations this treatment has undergone since its emergence, taking into consideration the relevance of this discussion to understand and confront the challenges faced by TA practices today. Emphasizing the changes that concern this kind of treatment, either the demand for this practice and its objectives or the profile of those who carry it out (TA), we focus on emergencies and on the subsequent developments that come from the concern of the TAS regarding the management of affective and significant exchanges between them and their patients. Such concern has conducted them to an effort of theoretical TA systematizing, with raises important questions about the relationship of TA with the knowledge about what accredits them to practice this function.

Keywords: Therapeutic accompaniment. Therapistis. Psychoanalysis. Knowledge acquisition.

Resumen: Abordando el acompañamiento terapéutico (AT) desde una perspectiva histórica, el artículo tiene como objetivo enfocar algunas transformaciones por las cuales esa modalidad de tratamiento pasó desde su surgimiento, mostrando su relevancia para la comprensión y el enfrentamiento de algunos desafíos con que se depara hoy. Destacando mudanzas que conciernen tanto a la demanda por esa práctica como sus objetivos y el perfil de aquél que la desempeña (AT), focalizamos la emergencia y los desdoblamientos de una preocupación de los acompañantes terapéuticos con el manejo del vínculo y de la escucha. Tal preocupación los ha conducido a un esfuerzo de sistematización teórica del acompañamiento terapéutico que levanta importantes cuestiones acerca de la relación del AT con el saber que lo credencia a practicar su función. Palabras clave: Acompañamiento terapéutico. Terapeuta. Psicoanálisis. Adquisicion del conocimiento.

A prática do acompanhamento terapêutico (AT) em foco neste trabalho surge como prática destinada àqueles pacientes acometidos por transtornos mentais ou por sofrimento psíquico que, por razões variadas, requerem mais (ou menos) do que oferecem os espaços tradicionalmente destinados ao seu tratamento, ou seja: clínicas, hospitais psiquiátricos e consultórios. Mais do que isso, é necessário acrescentar que o AT é uma prática itinerante, ou nômade (Rolnik, 2000). Se de fato acontece fora do hospital e do consultório, também não tem outro espaço típico de realização. Caracteriza-se por ser um tratamento que se faz em movimento. $\mathrm{O}$ termo acompanhamento faz também alusão a isso. Não basta dizer que o AT ocorre na rua, ou na casa do paciente, ou que seria, por exemplo, um tratamento domiciliar. Não: o AT é um atendimento que passa por lugares sem se fixar. O movimento do AT junto ao sujeito acompanhado é uma parte fundamental desse tipo de atendimento, à qual vem somar-se a escuta clínica que, em seus diferentes matizes, está presente em todo tipo de psicoterapia.

Tal forma de tratamento pode ser desejável por uma série de motivos, sendo muito variadas as possíveis utilizações do AT. Tendo isso em vista, advertimos que o que se segue abaixo focaliza o AT dirigido a sujeitos com transtornos tipicamente abordados no campo da psiquiatria, porém não a pessoas portadoras de necessidades especiais que possuem comprometimento do desenvolvimento físico e/ou mental ou diferentes tipos de demência cuja origem seja claramente relacionada a uma alteração na anatomia ou fisiologia cerebral. Neste trabalho, fazemos uma apresentação do AT enfocando as transformações pelas quais essa modalidade de tratamento passou desde seu surgimento. Destacando as mudanças sofridas por essa prática e a mudança do perfil daquele que a desempenha (AT) como duas de suas maiores 
modificações ao longo do tempo, propomonos a fazer esclarecimentos preliminares sobre o que consideramos uma das mais importantes, senão a mais importante consequência dessa dupla mudança, a saber, a emergência de uma preocupação dos ATs com o manejo do vínculo e da escuta, o que, por sua vez, os vem conduzindo a um esforço de sistematização teórica do AT que levanta uma série de questões acerca da sua relação com o saber.

\section{AT: os novos usos e configurações dessa prática}

Historicamente, o trabalho de AT foi requisitado por psiquiatras (em um número menor de vezes, por psicólogos clínicos, psicanalistas, etc.) como uma espécie de substituição da internação. Assim, equipes com quatro ou cinco ATs revezavam-se noite e dia em um atendimento de 24 horas/dia. Passada a crise do paciente, o AT diminuía progressivamente até que era interrompido.

Com o passar do tempo, seja porque tal modelo se tornou oneroso para a maioria das famílias, seja porque novas descobertas foram feitas acerca dos usos possíveis do AT, este pôde passar a ser feito também em cargas horárias menores (Equipe de acompanhantes terapêuticos do hospital dia A Casa, 1991; Reis Neto, 1995). Todo tipo de configuração horária passa a ser possível, na medida em que se entenda o AT não apenas como uma substituição da internação mas também como um trabalho que tem a especificidade de ser feito, como dissemos acima, em movimento, no espaço público e domiciliar, balizado por uma escuta clínica.

Na prática, no caso mais frequente, o psiquiatra entra em contato com uma equipe de ATs, solicitando atendimento para um de seus pacientes. Um dos representantes da equipe procura a família ou o paciente para apresentar o trabalho e estabelecer o contrato. Com isso, ficarão definidos o número de horas de atendimento, o ritmo do trabalho (por exemplo, 12 horas por semana podem ser distribuídas em três visitas de 4 horas ou quatro visitas de 3 horas), o número de membros da equipe, os honorários e o projeto terapêutico específico para o caso em questão.

Se, com o tempo, tornou-se comum o uso do AT em cargas horárias menores, tal fato refletiu a criação e a exploração de uma nova demanda, na qual o AT era solicitado não apenas para evitar a internação ou oferecer atenção em tempo integral mas também para oferecer a exploração conjunta do espaço público e domiciliar pelo par formado por AT e sujeito.

Esse tipo de configuração implica todos os cuidados a serem tomados quando se trata de um trabalho em equipe. Por um lado, temos uma equipe de ATs que, por sua vez irá se juntar a um psiquiatra e, eventualmente, a representantes de outras instâncias terapêuticas; por outro lado, o trabalho coloca o AT frente não apenas ao sujeito acompanhado, mas também, pelo menos em um grande número de vezes, a sua família e ao círculo social mais imediato. Trata-se, portanto, de um trabalho com uma forte característica grupal, ainda que mereçam também toda atenção os momentos em que AT e sujeito acompanhado se encontram sozinhos ou os vínculos singulares estabelecidos entre cada AT e sujeito acompanhado e seus familiares. $\mathrm{O}$ que se constrói assim com o andamento de um trabalho de AT é uma complexa rede de relações, potencialmente terapêuticas, mas que devem ser consideradas em toda a sua delicadeza para não gerarem efeitos iatrogênicos.

Em um trabalho que frequentemente envolve uma equipe de terapeutas e uma famíllia, as múltiplas relações que se estabelecem exigem manejo hábil, sobretudo quando o AT é lançado no interior da própria casa de seu paciente e quando consideramos que é da própria função do AT trabalhar em uma 
Para Freud

(1924/1969), o delírio constitui uma tentativa

de autocura, de recomposição dos investimentos libidinais nos objetos. posição mais simétrica do que o comum nas práticas psicoterapêuticas. Cabe ao AT permitir-se ser um pouco ele mesmo, ao que voltaremos mais abaixo, o que o coloca em uma fronteira delicada entre o ato clínico e a cumplicidade com os sintomas de seu acompanhado e com a família.

É comum que a equipe de profissionais envolvida em um determinado caso estabeleça formas de discussão do andamento do trabalho, o que dá a essa equipe um caráter interdisciplinar. Além das reuniões de equipe geral nas quais se discute o caso em andamento, as equipes de AT podem também fazer reuniões de mini-equipe, que incluem somente os ATs que acompanham determinado sujeito, ou mesmo optarem por supervisores de sua preferência para abordarem aspectos específicos do caso atendido. Vejamos agora algumas das situações típicas nas quais tal tipo de trabalho pode tornar-se desejável.

Imaginem o caso do sujeito delirante cujos laços sociais foram restringindo-se progressivamente, sendo reduzidos a uns poucos outros, integrados ao delírio. O sujeito pode estar recolhido há anos em seu quarto redigindo um livro sagrado, ou pode sair apenas para investigar uma rede que vem apertando o cerco em torno dele, eventualmente denunciando-a a polícia; ou pensemos em um sujeito deprimido, cujo risco de suicídio não seja avaliado como iminente ${ }^{1}$, ou ainda o adito que, quando só, não pode evitar o recurso às drogas, ainda que eventualmente o deseje.

Em todos esses casos, o AT pode, dentre outras coisas, cumprir o objetivo de evitar uma eventual internação, na medida em que compõe um aparato terapêutico extra muros capaz de oferecer uma contenção simbólica àquilo de excessivo que poderia levar à internação, e isso mesmo quando não é utilizado em uma carga horária extensa. Via de regra, o trabalho de AT, por mais que frequentemente implique algo próximo a um corpo a corpo entre AT e sujeito acompanhado, não inclui contenção física senão dentro de limites simbólicos, quando ela vale muito mais pela pantomima do não do que pelo uso efetivo de força física. Por outro lado, o AT implica a participação do sujeito acompanhado em um acordo que pode ser evocado em momentos-limite como forma de evitar o desencadeamento de situações que usualmente podem levar ao recurso da internação ou a alguma forma de exclusão do sujeito em relação à sua comunidade. Em casos determinados, seja pela menor gravidade, seja pelas características do sujeito, mesmo poucas horas de acompanhamento terminam por produzir ou para colaborar com a promoção do que chamamos acima, em sentido largo, de contenção simbólica.

Sabemos, por exemplo, o quanto a psicose pode incidir restringindo os vínculos do sujeito. Para Freud (1924/1969), o delírio constitui uma tentativa de autocura, de recomposição dos investimentos libidinais nos objetos. Entretanto, o que distingue o delírio, muito mais do que sua inadequação face a qualquer suposta realidade, é o fato de ele não promover o laço social; um delírio compartilhado socialmente deixa de ser delírio, independentemente do caráter mais ou menos bizarro do que manifeste, daí que o sujeito delirante se veja tantas vezes condenado a uma solidão ou reclusão nem sempre confortável para ele. Em casos assim, o AT pode facilitar a criação de novos laços, oferecendo como recursos tanto a escuta que abre à singularidade do delírio quanto o deslocamento compartilhado pelo espaço público, capaz de abrir ao psicótico novas possibilidades, pelo diverso e inusitado que tal espaço tem a oferecer.

Se muitas vezes é pelo início de um AT que um sujeito poderá voltar a frequentar determinada atividade (laço social), é também porque o AT é oferecido que o sujeito pode começar a construir alguma elaboração simbólica (no sentido de pôr em palavras) dos fenômenos invasivos que frequentemente 
estão manifestos na psicose paranóica ou na esquizofrenia. A oferta de uma escuta pelo AT pode ser eficaz exatamente na medida em que é oferecida no contexto de um deslocamento compartilhado no espaço público. Não quer dizer que seja sempre assim, mas, conforme avaliação pode ser o caso.

É preciso, quanto a isso, levar em conta que estamos falando de sujeitos em uma posição frequentemente muito avessa ao contexto oferecido pelo setting do consultório. Este constitui um espaço no qual todo peso é colocado sobre o que se fala. No AT, há o peso do que se faz - e isso para além do que se faz quando se fala. Nesse sentido, a fala pode emergir porque não tão diretamente chamada a ocupar o centro do palco. Além disso, o deslocamento compartilhado no espaço público faz surgir situações nas quais o AT atuará com sua escuta in loco, quer dizer, no momento mesmo em que o delírio ou alucinação surgem no contexto social. Isso permite e mesmo exige algum tipo de manejo cuja direção trará o selo das diferentes orientações teóricas passíveis de serem seguidas em uma clínica de AT.

Por sua vez, a presença de um AT junto a um sujeito deprimido ou melancólico pode servir às necessidades quase sempre presentes de atenção e oferecer uma possibilidade de troca para alguém que se fecha cada vez mais, seja no vazio subjetivo que o acomete paralelamente a mal-estar e a indisposição física, seja em delírios de indignidade. Tais sujeitos muitas vezes causam preocupações ao serem deixados sós, entregues a uma dinâmica mórbida, contra a qual o AT pode ser utilizado, ainda que isso não signifique uma solução definitiva ou suficiente para a cura almejada.

Finalmente, o sujeito adicto pode apresentar duas manifestações básicas: estar ou não interessado em abandonar as drogas. No caso de haver esse interesse, o AT pode funcionar como um apoio para que resista à tentação.
Poder-se-ia dizer, porém, que, nesse caso, o AT é apenas um vigia, ou uma babá, mas não é bem assim: enquanto o AT oferece apoio, uma série de trocas significativas se estabelece entre ele e o sujeito, trocas que podem levar a modificação considerada benéfica para a cura, sob diversos pontos de vista teóricoclínicos. A maior parte disso pode ser válida também no caso do sujeito adicto que não manifeste o desejo de abandonar a droga. Porém, como aconteceria em qualquer outra modalidade psicoterapêutica, nesse caso, haveria uma dificuldade a mais, qual seja, a de procurar criar no sujeito senão o desejo de abandonar a droga, pelo menos o desejo de se tratar, o que, de outra forma, tornaria vão todo o esforço terapêutico.

A indicação de AT a sujeitos que não desejam se tratar e/ou não reconhecem estarem doentes não acontece apenas no caso de pacientes adictos. Trata-se sempre de uma situação delicada, principalmente quando a equipe quer respeitar ao máximo a singularidade dos modos de estar no mundo, sem querer avaliá-los tendo por parâmetro um ideal pré-concebido. Há casos, por exemplo, em que o sujeito é confrontado (psiquiatra, família) com a opção: ser internado ou aceitar o AT. Ele pode acabar aceitando o AT e, nessas condições, o trabalho pode surtir efeitos interessantes. Mas há também aqueles casos em que a negativa do sujeito parece deixar espaço para que se entenda que o tratamento que inclui o AT não está sendo efetivamente recusado, ainda que verbalmente o sujeito pareça indicá-lo. Já quando o sujeito manifesta uma efetiva recusa ao tratamento, então se torna inviável o trabalho pelo AT, pelo menos quando se deseja com este mais do que simples vigilância.

Voltando aos casos de adição, o AT pode, sim, funcionar como um limite ao uso de substância pelo sujeito, mesmo quando este não manifesta desejá-lo; são situações que não estão excluídas do leque de possibilidades do AT, ainda que tragam uma questão ética essencial (oferecer tratamento a quem não 
o deseja). É evidente que não será sempre possível conseguir isso pelo uso do AT, mas queremos principalmente destacar que, mesmo quando o AT cumpre essa função, ele a cumpre pela mediação da escuta que oferece e pelo vínculo que estabelece com seu acompanhado.

Em todos os três casos mencionados anteriormente, como ressaltamos, o AT pode funcionar no sentido de evitar a internação. Mas essa não é a única finalidade que se pode alcançar com tal tipo de trabalho. Definir o AT como o que evita a internação é recorrer a uma definição negativa no sentido em que aponta o que o AT evita. Com os diferentes usos do AT, fica mais claro aquilo que esse trabalho traz, mesmo quando o que está em jogo não é uma ameaça de internação do sujeito. Voltaremos a esse assunto.

\section{Da comunidade terapêutica para a rua e do leigo ao profissional}

Acabamos de destacar algumas modificações pelas quais o AT vem passando ao longo de sua história, principalmente no que diz respeito aos novos usos e configurações dessa prática. Paralelamente a essas mudanças, também o perfil de quem faz o acompanhamento vem se modificando ao longo do tempo.

É curioso notar que, inicialmente, o trabalho de AT era feito muitas vezes por leigos (Reis Neto, 1995), ou, pelo menos, por profissionais dos quais não se exigia formação ou virtuosismo teórico. Os ATs surgem no interior de comunidades terapêuticas argentinas, sendo, mais ou menos nessa época - final da década de sessenta incorporados ao trabalho da Clínica Pinel, de Porto Alegre. Preferia-se, então, que o AT fosse um leigo, ou seja, alguém que não fizesse de seus conhecimentos teóricos um instrumento para o trabalho com os pacientes. O tipo de ideologia que atravessava em maior ou menor grau as comunidades terapêuticas favorecia esse tipo de posição, pela contestação de identidades rigidamente delimitadas e pelo investimento na constituição de um ambiente terapêutico facilitador da aprendizagem social como maior força no tratamento (Jones, 1968).

Dentro da clínica, os futuros ATs permaneciam em um tipo de troca o mais simétrica possível com os pacientes, procurando sempre engajálos em atividades compartilhadas com essa comunidade. Porém, havia também as saídas acompanhadas, para finalidades diversas, como consulta médica, atividades de lazer, volta progressiva ao lar e convívio com os familiares. Tais saídas prenunciavam o uso do AT que passaria a existir em seguida, quando esse trabalho passou a ser oferecido, como já destacamos, a pacientes não internados.

Nesse novo momento, alguns psiquiatras começaram a chamar os ATs para atuar junto a seus pacientes, cumprindo finalidades diversas, entre as quais evitar a internação. Como já mencionado, com o tempo, diversificam-se os usos do AT ao mesmo tempo em que, progressivamente, os ATs foram deixando de ser leigos, tornando-se majoritariamente estudantes de Psicologia e, em um número menor de vezes, de psiquiatria. Ainda um pouco mais tarde, os estudantes seriam substituídos por profissionais, muitas vezes psicólogos clínicos, que hoje procuram dar a essa prática um estatuto teórico mais preciso. Registre-se aqui, pois, a dupla mudança, que atinge tanto os usos feitos dessa prática quanto o perfil daqueles que a realizam.

Essa dupla mudança não deixa de ter suas reverberações na leitura teórico/clínica que se faz do AT. Esta será importante na delimitação dos objetivos do trabalho e também na exploração da escuta oferecida pelo AT ao sujeito durante o seu trabalho e na mediação que eventualmente venha a fazer entre este e sua família. É fácil notar que o mero deslocamento compartilhado entre AT e sujeito não apresenta, em si mesmo, valor clínico considerável, que somente irá surgir 
na medida em que tal atividade se faça acompanhar por algum tipo de elaboração, por parte do sujeito, do momento que vive e do que se projeta como futuro em sua vida. Assim, a experiência de acompanhar tem remetido ATs a pensarem como manejar de modo mais profícuo, em uma perspectiva clínica, a escuta e o vínculo afetivo que é sempre chamado a estabelecer com o sujeito que acompanha (Equipe do hospital-dia A Casa, 1991; Mauer \& Resnizky, 1985; Palombini, Chnaiderman, Jover, Ritchter, Benevides, \& Raymundo, 2004; Reis Neto, 1995).

\section{O que sabe o AT?}

Há uma relação do trabalho do AT com o dos enfermeiros psiquiátricos, no sentido de que atuavam em um espaço e tempo semelhantes, pelo menos no início da prática do AT, quando ainda eram utilizados em cargas horárias grandes, com uma função que também deveria atender aos objetivos de cuidar, medicar e vigiar (Ibrahim, 1991). A diferença seria justamente que, ao AT, Ihe é demandado um cuidado com o vínculo e a escuta. Não que a pessoa que fizesse a enfermagem antes não pudesse fazê-lo, porém, ao fazê-lo, tornou-se AT, e não mais enfermeiro. Há aqui uma problemática de nomenclatura, dos nomes utilizados para designar quem irá cumprir uma função e também uma questão relacionada à própria função. Os diferentes nomes utilizados para designar quem faz o AT confirmam a existência dessa controvérsia - atendente psiquiátrico, amigo qualificado, auxiliar psiquiátrico, acompanhante terapêutico, sendo esta a preferida entre os que fazem esse trabalho, por enfatizar o caráter clínico dessa prática e a sua autonomia em relação à psiquiatria (Ibrahim, 1991; Mauer \& Resnisky, 1985; Reis Neto, 1995).

Certo é, pois, o fato de que aparece como um invariante entre a diversidade de práticas de AT a orientação no sentido do cuidado com o vínculo e com a escuta. Logo, é bastante razoável que os ATs tenham começado, com o tempo, a interrogar o melhor modo de conduzir essa experiência, para a qual o recurso à sistematização teórica vem contribuir. Esse esforço de sistematização esbarra, contudo, na delicadeza de uma prática marcada desde seu início, conforme veremos abaixo, pela peculiaridade do tipo de saber que se demanda daquele que a desempenha.

Embora se possa ver um avanço na alteração do perfil de quem faz o acompanhamento - do leigo (que não sabe), para o estudante (que está aprendendo), culminando com o profissional de Psicologia clínica (aquele que sabe) -, é preciso um pouco de cuidado quanto a esse fato, pois, em primeiro lugar, a potência do trabalho de AT depende em parte da falta de saber do AT. Historicamente, lançou-se mão dessa atividade quando ofertas terapêuticas mais tradicionais fracassaram. $\mathrm{O}$ AT chegava então com a liberdade de atuar em um terreno no qual ninguém sabia muito bem o que poderia ser feito, embora algo devesse ser feito. Além disso, as circunstâncias de seu trabalho colocam o AT em uma posição de aparente simetria com os sujeitos que acompanha. Em sua circulação pela cidade, poderão estar no cinema, no restaurante, no show, na praia, etc., quando o AT terá que ser terapêutico sendo o mais ele mesmo possível. No campo das práticas psi, talvez em nenhuma se demande tanto do terapeuta uma presença corporal e de persona(lidade), como acontece no AT, e isso coloca o AT na fronteira entre um ser ele mesmo e ser um terapeuta.

Em segundo lugar, se houve progresso, é preciso que se saiba dizer o que o AT deve saber e para que deve sabê-lo. Ao AT, pediu-se também que ele cumprisse certas tarefas mais objetivas, como levar o sujeito até determinados lugares, dar medicação, não deixá-lo sozinho, impedir o uso de determinada substância, etc. Àqueles que lhe solicitavam isso (basicamente psiquiatras), pouco interessava sobre o que o AT conversaria com o sujeito durante o 
período em que estivessem juntos, desde que tais objetivos fossem cumpridos. Essa perspectiva deixa entender que o essencial da ação terapêutica do AT não está no que ele conversa com o sujeito.

Teríamos, de um lado, uma demanda mais subjetiva, bem menos precisa, de que o AT estabelecesse um vínculo e oferecesse uma escuta diferenciada, fosse lá o que isso quisesse dizer, e, de outro lado, teríamos uma série de tarefas de cuidado que o AT também deveria cumprir, mas que definitivamente não necessitariam de nenhuma formação superior para que pudessem ser executadas. Quando os ATs reclamam o reconhecimento do caráter clínico de sua prática, querem sempre apontar que é no manejo de sua escuta e do vínculo que se desdobra através de suas andanças com o sujeito que está o potencial de uma ação clínica no AT.

Se o AT era inicialmente feito por leigos, é porque, desde sua aparição no cenário psi, há um limite do saber inscrito nessa prática de modo peculiar. $\mathrm{O}$ fato de o AT surgir nas comunidades terapêuticas como um trabalho feito por um novo técnico - inicialmente chamado de amigo qualificado ou auxiliar psiquiátrico - e não pelos técnicos que já existiam então, deveu-se a uma operação que preservou as identidades já fixadas desses outros técnicos. Quem não tinha o saber eram os leigos, amigos qualificados ou auxiliares psiquiátricos, e não eles, os antigos técnicos conclamados pela ideologia das comunidades terapêuticas a questionar suas próprias identidades e funções face ao inusitado colocado pela loucura (Jones, 1972; Reis Neto, 1995). Nesse sentido, o surgimento dessa nova figura nas comunidades terapêuticas pode ser lida como sintoma, no sentido de que portou uma mensagem acerca de uma contradição não refletida das práticas psiquiátricas que serviram de solo para sua irrupção - sintoma que, portanto, deve ser escutado e não, eliminado.
Dizer que houve progresso no fato de o AT se ter tornado cada vez mais informado pela teoria pode equivaler a recalcar o fato de que inicialmente o AT tinha que ser leigo para ser terapêutico. Ao tornarem-se progressivamente informados teoricamente, os ATs não devem esquecer que há algo de leigo que deve ser preservado nesse trabalho. Não afirmamos que essa mudança seja ruim, porém considerá-la apenas segundo a linha de um progresso parece-nos insuficiente e mesmo inadequado para indicar os rumos que uma reflexão sobre o saber do AT deve tomar ${ }^{2}$.

Nesse contexto, a psicanálise tem ocupado um papel central para muitos que fazem o AT. Ela tem fornecido aos ATs ferramentas conceituais que alimentam muitas das tentativas de reflexão teórica sobre o valor dessa prática clínica. Os ATs ficam durante muito tempo com seus sujeitos acompanhados e, durante esse tempo, muito é dito e escutado, ao mesmo tempo em que pode ganhar densidade a relação estabelecida entre eles.

Submetido a essa experiência e encantado por ela, o AT é ajudado pela psicanálise na busca de dar um enquadramento teórico/clínico à delicada experiência que faz. A psicanálise permite ainda dar outra perspectiva à questão do saber/não saber do AT, na medida em que, para ela, a formação do clínico - e, portanto, do AT que se quer clínico - passa mais por sua análise pessoal, experiência de vida e leituras teóricas do que pela graduação, que transforma um leigo em estudante e depois em profissional.

Na medida em que o AT é chamado a estabelecer um vínculo e a oferecer uma escuta ao sujeito que acompanha, presume-se que isso é parte do que tornará sua atividade terapêutica. Essa demanda feita ao AT coloca-o de imediato no campo das psicoterapias e na problemática ligada ao manejo da sugestão e do fator mental. Conforme precisa indicação de Freud (1905/1969, p. 269), dirigindo-se aos médicos em defesa da psicoterapia: 
(...) vêm continuamente praticando a psicoterapia, mesmo quando não tendes nenhuma intenção de fazê-lo e disso não estais cônscios; é uma desvantagem, contudo, deixar o fator mental em vosso tratamento tão inteiramente nas mãos do paciente. Dessa forma, é impossível manter um controle sobre ele, administrá-lo em doses ou intensificá-lo. Não é um esforço justificável (...) procurar obter desse fator, utilizá-lo com uma finalidade, orientá-lo e fortalecê-lo? Isso e nada mais que isso é o que propõe a psicoterapia

Esse atravessamento do AT pela psicanálise gera a preocupação de que ele importe o modelo do analista para sua prática. Com isso, privilegiaria a escuta e os diálogos mais intimistas em detrimento do deslocamento pelo espaço público. Alternativamente, encontramos um texto de Deleuze (1992) sobre o que chama de intercessores, uma ideia que indica bem o que não pode ser perdido na prática do AT. O autor destaca a relevância de se considerar o movimento como contraponto aos pensamentos da origem que exigem um ponto fixo a partir do qual se apoiam. O intercessor pode ser pessoa, coisa ou animal (o que remete ao inusitado do espaço público), e faz junto, produzindo efeitos de mudança sem colocarse, contudo, a intenção de intervir no outro (o que já seria cair na posição de dominador). O AT, nessa perspectiva, poderia tanto atuar como intercessor quanto promover o encontro entre sujeito e intercessores.

De todo modo, importa que o AT não utilize a psicanálise para tornar-se um analista portátil e, de modo mais geral, qualquer outra teoria que o faça sentir-se um terapeuta de consultório portátil. Sejam quais forem os caminhos que tome a teorização do AT, ela deverá levar em conta que tal clínica se faz no espaço público e domiciliar, justamente aquilo que as clínicas de consultório fecharam e com boas justificativas teóricas para isso. Do mesmo modo, o AT abre ao sujeito, conforme mencionado anteriormente, um contato com sua personalidade, seus gostos, preferências, o que é delicado, mas que faz parte do trabalho do AT. Deve-se entender de que modo isso pode ser posto em acordo com uma direção clínica que baliza tanto o que o AT fala quanto o que ele faz - evidentemente não esquecendo que, ao falar, ele também faz alguma coisa.

\section{Considerações finais}

Conforme procuramos mostrar, surge como efeito das modificações sofridas tanto pelo trabalho do AT quanto pelo perfil do AT uma preocupação deste em melhor manejar o vínculo e a escuta que oferece ao sujeito acompanhado, para o que a psicanálise muito tem contribuído.

É certo que um esforço de teorização do AT, intrinsecamente ligado à questão sobre o que deve saber o $A T$, contribui para o refinamento dessa prática. Não se pode acusar os que desempenham uma prática que pretendem clínica de quererem teorizar sobre o que fazem. Tal esforço é louvável e merece ser incentivado. Seria lamentável, porém, que, com o tempo, o AT repetisse o erro que fez com que um dia surgisse um técnico psi destinado a assumir a ignorância que ameaçava os outros, no encontro com um sintoma que insistia em não se deixar enquadrar.

Nesse sentido, vale notar que o AT, por sua própria trajetória histórica como prática psi sempre mal instituída, sempre resistente à apreensão por um saber que the garanta contornos bem definidos, presta-se bem como instrumento aos esforços de constituição de uma prática em saúde mental que se permita interrogar a si mesma, característica dos movimentos de reforma psiquiátrica, como acontece no Brasil. A entrada do AT em serviços públicos de modo articulado aos CAPs seria, assim, possível e bem-vinda (Palombini, 2004; Pelliccioli, 2003). 


\section{Raymundo de Oliveira Reis Neto}

Doutor em psicologia clínica PUC/RJ, Psicanalista, Coordenador e Professor do Curso de Psicologia da Universidade Estácio de Sá, campus Nova Friburgo - Rio de Janeiro - RJ - Brasil.

E-mail: r.reisneto@gmail.com

\section{Ana Carolina Teixeira Pinto}

Pós-graduada em Teoria e Clínica Psicanalítica pela UNESA-NF, Psicóloga da Fundação Municipal de Saúde de Nova Friburgo e Coordenadora do Grupo de Acompanhamento Terapêutico Paripassu, Rio de Janeiro - RJ - Brasil.

E-mail: tpsicarol@hotmail.com

\section{Luiz Gustavo Azevedo Oliveira}

Pós-graduado em Teoria e Clínica Psicanalítica pela UNESA-NF, Psicólogo Clínico e Coordenador do Grupo de Acompanhamento Terapêutico Paripassu, Rio de Janeiro - RJ - Brasil.

E-mail: oliveirabirds@hotmail.com

\section{Endereço para envio de correspondência:}

Avenida Manoel Carneiro de Meneses, 2001, casa 3B. Mury, Nova Friburgo, Rio de Janeiro - RJ - Brasil. CEP: 28615-060

Deleuze, G. (1992). Os intercessores. In Deleuze, G., Conversações (pp. 151-168). Rio de Janeiro: 34 Letras.

Equipe de Acompanhantes Terapêuticos do Hospital Dia a Casa (1991). A rua como espaço clínico. São Paulo: Escuta.

Freud, S. (1969). Sobre a psicoterapia. In: Edição Standard Brasileira das obras Psicológicas completas de Sigmund Freud. (Vol. 7, pp. 267-282). Rio de Janeiro: Imago (Trabalho original publicado em 1905).

Freud, S. (1969). A perda da realidade na neurose e na psicose. In Edição Standard Brasileira das Obras Psicológicas Completas de Sigmund Freud (Vol. 19, pp. 229-238). Rio de Janeiro: Imago (Trabalho original publicado em 1924).

Ibrahim, C. M. (1991). Do louco à loucura: o percurso do auxiliar psiquiátrico no Rio de Janeiro. In Equipe de Acompanhantes Terapêuticos do Hospital Dia a Casa (Ed.), A Rua Como Espaço Clínico (pp. 43-49). São Paulo: Escuta.

Jones, M. (1972). A comunidade terapêutica. Rio de Janeiro: Vozes Ltda.

Mauer, S. K., \& Resnizky, S. (1985). Acompanhantes terapêuticos e pacientes psicóticos. Campinas, SP: Papirus Editora.
Miller, J. A. (1997). Patologia da ética. In J. A. Miller, Lacan Elucidado (pp. 329-386). Rio de Janeiro: Jorge Zahar.

Palombini, A. L., Chnaiderman, M., Jover, E. R., Ritchter, E. P., Benevides, L. G.,

Raymundo, M. B. et al. (2004). Acompanhamento terapêutico na rede pública: a clínica em movimento. Porto Alegre: UFRGS.

Pitiá, A. C. A., \& Santos, M. A. (2005). Acompanhamento terapêutico: a construção de

uma estratégia clínica. São Paulo: Vetor Editora.

Reis Neto, R. O. (1995). Acompanhamento terapêutico: emergência e trajetóriahistórica de uma prática em saúde mental no Rio de Janeiro. Dissertação de Mestrado, Instituto de Psicologia, Pontifícia Universidade Católica do Rio de Janeiro, Rio de Janeiro.

Soller, C. (1989). Pérdida y culpa en la melancolia. In Clinica de las psicosis (pp. 33-43). Buenos Aires: Manantial. 